\title{
GENEALOGÍA DE LA ASIMILACIÓN DE LO NORMATIVO: ANÁLISIS DEL ESTUDIO DEL DERECHO EN LOS INICIOS DE LAS UNIVERSIDADES OCCIDENTALES*
}

\author{
Édgar Hernán Fuentes Contreras ${ }^{(a)}$ \\ Luz Eliyer Cárdenas Contreras ${ }^{(b)}$
}

\author{
GENEALOGY OF THE ASSIMILATION OF NORMATIVITY: ANALYSIS OF \\ THE STUDY OF LAW IN THE ORIGIN OF WESTERN UNIVERSITIES
}

GENEALOGIA ASSIMILAR NORMATIVA: ANÁLISE DO ESTUDO

DO DIREITO NO INÍCIO DAS UNIVERSIDADES OCIDENTAIS

Fecha de recepción: $1 .^{\circ}$ de agosto del 2017

Fecha de aprobación: 30 de agosto del 2017

Sugerencia de citación:

Fuentes Contreras E. H y Cárdenas Contreras, L. E. (2017). Genealogía de la asimilación de lo normativo: Análisis del estudio del Derecho en los inicios de las universidades occidentales. Razón Crítica, 3, 85-110 , doi: http://dx.doi.org/10.21789/25007807.1236

* Componentes del presente artículo se presentan como resultado parcial del proyecto de innovación pedagógica: "Formación jurídica a partir de la metodología de casos" adscrito al Grupo de Investigación Derecho y Globalización del programa de Derecho de la Facultad de Ciencias Sociales de la Universidad de Bogotá Jorge Tadeo Lozano (Colombia). Contenidos parciales del artículo se presentaron, como ponencia, en el evento: "Foro: Estudios Interdisciplinarios en Derecho" en la Universidad de los Andes (2017).

(a) Abogado de la Universidad de Antioquia (Colombia). Máster en Derecho y en Derecho Constitucional de la Universidad Nacional de Colombia y Universidad de Sevilla (España), respectivamente. Especialista en Derecho Constitucional de la Universidad Externado de Colombia. Doctorando en Derecho Constitucional, con mención internacional de la Universidad de Sevilla. Director del Área de Derecho Público de la Universidad de Bogotá Jorge Tadeo Lozano, Bogotá D.C. - Colombia. http://orcid.org/0000-0002-1066-0999. edgar.fuentes@utadeo.edu.co (b) Abogada de la Corporación Universitaria Republicana (Colombia) y Especialista en Derecho Público de la misma universidad. Actualmente, adelantando estudios de Maestría en Derecho del Estado con énfasis en Derecho Público de la Universidad Externado de Colombia, Bogotá D.C. Colombia. http://orcid.org/0000-0001-7986-4343. eliyercardenas@gmail.com 


\section{R E S U M E N}

El presente artículo se encarga de efectuar un estudio de carácter genealógico de la enseñanza del Derecho; para esto, acude a una metodología descriptivacorrelacional de los modelos de enseñanza y aprendizaje de las primeras universidades occidentales, nacientes al final de la Alta Edad Media. Durante tres acápites se exponen, primero, la aparición de las universidades y de las escuelas de Derecho, después los llamados mos italicus y mos gallicus, para finalizar con una correlación de las escuelas posteriores y los modelos originarios. Finalmente, se acceden a las conclusiones donde se muestra la dependencia de estructuras medievales y su prolongación genética, incluso en contextos contemporáneos.

PALABRAS CLAVE: enseñanza del Derecho, historia del Derecho, mos italicus, mos gallicus, universidades 


\section{A B S T R A C T}

This paper carries out a genealogical study on the teaching of law; for that purpose, it uses a descriptive-correlational analysis of the teaching and learning models of the first Western universities, borned at the end of the High Middle Ages. It presents in three sections the emergence of universities and law schools; the socalled mos italicus and mos gallicus, and finally establishes a correlation between the later schools with the original models. Finally, we reach the conclusions about the dependence of medieval structures and their genetic extension, even in contemporary contexts..

KEYWORDS: teaching Law, history of Law, mos italicus, mos gallicus, universities

\section{R E S U M O}

Este artigo objetiva fazer um estudo genealógico do ensino jurídico. Para isso, utiliza-se de uma metodologia descritiva-correlacional dos modelos de ensino e aprendizagem das primeiras universidades ocidentais, que surgiram ao final da Alta Idade Média. Durante três capítulos, são expostos, em primeiro lugar, o surgimento de universidades e escolas de direito, depois os então chamado mos italicus e mos gallicus, e, por fim, uma correlação das escolas subsequentes e dos modelos originários. Finalmente, tem-se a conclusão na qual se demonstra a dependência de estruturas medievais e sua extensão genética, mesmo em contextos contemporâneos.

PALAVRAS-CHAVE: ensino do Direito, história do Direito, mos italicus, mos gallicus, universidades 


\section{N T R O D U C C I Ó N}

Una de las circunstancias casi inevitables en las discusiones jurídicas se encuentra vinculada con el problema del carácter científico del derecho, el cual suele ser un asunto recurrente y casi invasivo en los diversos abordajes históricos y filosóficos que buscan estructurar una visión de lo normativo. Dicha discusión comporta una pretensión que se liga con el estatus que se le puede ofrecer a la ciencia jurídica, como disciplina, dentro de los estándares propios de las revoluciones científicas de los siglos XVI y XVII (Kuhn, 2002). Sin embargo, lo cierto es que el derecho ha estado atado a los claustros universitarios y a las universidades mismas desde su aparición en hacia finales de la Alta Edad Media. Si bien ello no implica necesariamente la ausencia de centros y formas de asimilación precedentes (Agudo, 2010), parece innegable que "[1]a historia de las universidades puede proporcionar buenos elementos para un estudio más arraigado del proceso evolutivo de las ciencias" (Peset, 1987, p. 106), en ocasión que al final, “[e]l científico adquiere su formación en las aulas, en buena parte de los casos [...] [y] Las universidades, junto a las academias, nos deparan una sociología del saber más amplia que la simple vida particular de los científicos” (Peset, 1987, p. 106). 
Así las cosas, la profesión jurídica ${ }^{1}$ se ha establecido, en el ámbito occidental, como un punto de partida para la asimilación de lo jurídico y, en buena parte de los casos, como la forma de interrelacionar al conglomerado social con las manifestaciones normativas que regulan su comportamiento y los hacen sujetos de derechos y obligaciones.

Ahora, en un contexto como el actual donde existe un notorio número creciente de abogados y de la oferta académica de programas universitarios de derecho², hay también un distanciamiento de estos profesionales de los sectores más influyentes en el mercado laboral, y se extiende una marcada desconfianza sobre estos. Por esta razón, el proceso formativo de las universidades resulta un tema de interés y de gran influencia para la determinación de lo que pueden aportar los abogados a su entorno, tanto desde los contenidos científicos como sociales.

En busca de dichos parámetros y basándose en la pregunta de investigación (¿cuáles son los modelos de asimilación respecto a lo jurídico en el contexto de las primeras universidades occidentales?), el actual texto se presenta como un resultado parcial de investigación en el cual se abordó, con una pretensión correlacional, las primeras formas de asimilación normativa durante la aparición de las universidades occidentales. Esto permite establecer los métodos y parámetros que cimentaron, y en algunos casos siguen vigentes, la profesionalización y la práctica jurídica.

1 Si bien tratar a los profesionales del derecho como una unidad o un colectivo homogéneo puede ser erróneo, dado que ser abogado en México o en España no es lo mismo, como tampoco lo sería un abogado español actual que otro bajo la formación decimonónica (debido a que los requisitos para ser abogado no solo difieren de país en país, sino también, de acuerdo a las épocas de formación), se ha optado por aludir a los profesionales del derecho como aquellas personas que ejercen diversos oficios, pero para los cuales han recibido un adiestramiento bajo los estándares de una carrera profesional. En esa medida, la definición empleada no diferenciará ni exigirá el ejercicio de la profesión jurídica en un campo específico, al tiempo que no admite en ella a aquellas personas vinculadas con prácticas jurídicas, pero que carecen de una titulación universitaria, es decir, de un grado académico de educación superior tras la formación profesional y completar los requisitos previstos por el país y/o institución educativa para obtener dicho grado. Al respecto véanse Pérez (2004, 2005) y Binder (2005).

2 Por ejemplo, en el caso colombiano, en el periodo de 1990 al 2002, se pasó de 38 programas de Derecho ofertados por 32 instituciones de educación superior a 147 programas ofertados por 63 instituciones; en el 2011 hubo 219 programas ofertados (entre activos e inactivos). En el primer lapso, hubo un incremento superior al $272,2 \%$ respecto a los programas de derechos ofrecidos y casi el doble respecto a las instituciones habilitadas para ofertar dicho programa; mientras que, del 2002 al 2011, se incrementaron los programas en un $148,98 \%$. 
Para la satisfacción del objetivo planteado, el artículo se dividirá en tres acápites: el primero, encargado de aludir a la formación de las universidades occidentales y el derecho como pilar de formación de éstas; en el segundo, se expondrán los posteriores manifestaciones y modelos de formación jurídica, mediante la distinción de los llamados mos italicus tardío y mos gallicus; por último, se verá la influencia posterior que tuvieron en los modelos de enseñanza subsiguientes, para finalizar con las respectivas conclusiones.

\section{El surgimiento de las universidades occidentales y Bolonia como guía de lo normativo}

Tal como se anticipaba, el elemento diferenciador que se ha escogido para hablar de los profesionales jurídicos es la formación universitaria. Por ello, se hace totalmente necesario, para la delimitación espacial y temporal, que existan universidades. Por consiguiente, el estudio dará inicio con el nacimiento de estas a finales del siglo XI en pleno cierre del alto medievo. Empero, y si bien es común emplear dicho término para referirse a instituciones, es importante resaltar que originalmente cuando se empleaba el término universitas $^{3}$ este no hacía referencia a un espacio donde se dictaban clases o se desarrollaba una guía o un programa de estudio con fines de profesionalizarse:

La universitas, término que podía ser substituido por los de corpus, collegium, societas, communio, consortium, consiste en la corporación, cuya especificación podía ser de scholarium o de magistrorum, dando origen de esta manera a las dos formas típicas de tal organismo, bien como corporación de estudiantes, cuya finalidad era obtener grados académicos para ocupar puestos en la sociedad, o bien como corporación de enseñantes, quienes se dedicaban a la investigación (Salvador, 2008, pp. 132-133)

3 La palabra 'Universidad' deviene del latín Universitas, como nombre abstracto formado sobre el adjetivo universus- $a$-um (todo, entero, universal), y a la vez derivado de unus-a-um (uno). Esta palabra en latín medieval, se utilizó para designar cualquier comunidad o corporación considerada en su aspecto colectivo y, aún posteriormente, denotando un cuerpo dedicado a la enseñanza y a la educación requería la adición de un complemento para completar su significado: 'Universitas Magistrorum et Scholarium' (ayuntamiento de maestros y de escolares)” (Velásquez y Morales, 2010, p. 4). 
Sería solo hasta "fines del siglo XIV [cuando] la palabra universitas empezó a emplearse sola, con el significado exclusivo de comunidad de maestros y de discípulos, cuya existencia corporativa había sido reconocida por la autoridad eclesiástica o civil, o por ambas a la vez (Rashdall)" (Salvador, 2008, p. 133), y los cuales asistían a un centro de enseñanza o studium desde el siglo $\mathrm{XI}^{[4]}$.

El auge que empezaron a poseer dichos centros haría que estos reemplazaran los espacios y formas precedentes de trasmisión del conocimiento. Justamente, el apogeo de las universidades y los studium haría que las escuelas catedralicias y monásticas, entre otros núcleos de instrucción que yacían por toda Europa, fueran extinguiéndose poco a poco, hasta que para finales del siglo XI y comienzo del XII, se impusieran las universidades debido a

[...] la aparición de maestros de prestigio a los que acudían alumnos venidos de diversas partes; la acción planificadora del Estado, consciente de la importancia de preparar sus propios funcionarios, e incluso la acción de la Iglesia, preocupada por una mejor formación de su clero o la misma expansión y arraigo de los movimientos corporativos[; así como, las] necesidades profesionales y el ansia de conocimientos [que se experimentaron] de modo más intenso [permitieron que] la misma Iglesia [tuviese] un medio de adquirir las técnicas expositivas y demostrativas necesarias para su apostolado, una base jurídica para la elaboración de las nuevas legislaciones eclesiásticas o incluso la fuente de conocimientos para participar en las funciones del Estado (Barcala, 1985, p. 84).

Dichas circunstancias ocasionaron, no de forma coincidente, que las primeras universidades se forjaran alrededor de la Iglesia católica y que, adicionalmente, tuviera un espacio privilegiado la enseñanza jurídica o del derecho.

En el caso jurídico, la experiencia universitaria tendría como punto de origen y referencia el studium de Bolonia ${ }^{5}$ y los estudios

4 "La designación más antigua y usual en la Edad Media era studium, y después studium generale, designación que implica un centro de instrucción para todos; es decir, el generale se refería al público que podía frecuentarlo, de diversas nacionalidades, credos y razas, y al ámbito de los estudios que en él se realizaban" (Salvador, 2008, p. 133).

5 "La historia de la educación registra que la primera Universidad fue Bolonia (Italia), 
de leyes romanas desde un punto de vista histórico y lingüístico.

La razón de este objeto de estudio tiene dos teorías: una fantástica, basada en el descubrimiento de Irnero ${ }^{6}$, y otra derivada de su continuo uso del mismo, sin dejarse de lado los cambios sufridos por su aplicación y evolución. Lejano a la explicación fantástica del descubrimiento $^{7}$, se considera más viable aceptar que el derecho romano continuaba, de alguna manera, siendo empleado dentro de las manifestaciones jurídicas diversas que existían en el medioevo:

Por eso es imprescindible hacer tres aseveraciones al respecto. La primera es que el derecho romano no se extinguió con el perecimiento del Imperio romano de Occidente, sino que fue recibido en diversas formas y medidas por los nuevos pueblos que surgieron de las ruinas de éste a través de las leyes romanobárbaras. La segunda es que no sólo el derecho justinianeo fue y ha sido objeto de recepción en el mundo europeo, sino también el derecho prejustinianeo, tanto en el ámbito legislativo (leges)

aunque se discute si no fue más bien Salermo que era una verdadera escuela de medicina" (Velásquez y Morales, 2010, p. 8). "Algunos sostienen que la primer a universidad fue la de Salerno (siglo XI), pero lo cierto es que Salerno no pasó de ser más que una escuela de medicina, y no, una verdadera universidad. Es así que la gloria de ser la primera universidad que conoció el mundo suele reservarse a la Universidad de Bolonia, donde si bien los estudios jurídicos tenían preeminencia, a su lado también se impartían los de filosofía, teología, matemáticas y astronomía, medicina y farmacia. Suele aceptarse el año 1119, o sea a principios del siglo XII, como la fecha más aproximada de la fundación de la Universidad de Bolonia. Otros dicen que 1088 (fecha oficial de la creación de la Escuela de Derecho). La siguiente sería la de París (1150), Oxford (1167), Palencia (1208), Cambridge (1209), Salamanca (1220), Nápoles (1224), Heidelberg (1385), Alcalá (1508). Entre las más antiguas están también la de Praga y Viena” (Tünnermann, 2003, p. 26).

6 " $[\ldots]$ al mismo Irnerio se le reconoce haber realizado un inesperado descubrimiento -seguramente en un oscuro rincón de una biblioteca de Pisa- abandonado y cubierto de polvo, del codex secundus, que se calificaba como la codificación más acabada del derecho romano. Empero, Paul Koschaker advierte estar confirmado por la leyenda que el emperador Lotario II (1135) obtuvo ayuda bélica de los pisanos en la conquista de Amalfi, a la cual correspondió con el regalo que hizo a estos del códice florentino, que era un manuscrito del Digesto; agrega el autor mencionado que de ese obsequio resultó que el emperador promulgara una ley sugerida por Irnerio o de su protectora Matilde, que ordenaba la aplicación del derecho romano en los litigios que se sustanciaran ante los tribunales, así como la enseñanza pública de esa normatividad. A este respecto, el comentarista observa que autores como Caillemer, Chenon, Esmein-Genestal y Fleischmann consideran que tal leyenda que recomendaba la observancia del derecho romano constituía una severa derrota para el prestigio del Imperio alemán. Sin embargo, acepta -a la vez- que la misma versión fue aceptada durante muchos siglos por los juristas alemanes, pero que H. Conring la impugnó en su escrito "De origine iuris germanici" (1643) y que Savigny demostró su falsedad” (Magallón, 2002, p. 158).

7 "El descubrimiento de una copia de la compilación de Justiniano, cerca del año 1080, fue recibido con el mismo espíritu con que se habría recibido el descubrimiento de un ejemplar de una continuación, perdida durante siglos, del Antiguo Testamento" (Berman, 1996, 133). 
como en el ámbito doctrinal (iura). La tercera es que partes del propio derecho justinianeo se utilizaron en Occidente antes del “descubrimiento" de Irnerio (Bernal, 2010, pp. 107-108) ${ }^{8}$.

En esa medida, resultaba de gran atractivo para las primeras universidades el estudio del derecho romano. Este interés naciente provocó lo que sería conocido como la segunda vida o recepción del derecho romano o el renacimiento de dicho derecho ${ }^{9}$. Bolonia, como gran involucrada de este renacimiento, estableció un modelo propio de enseñanza dirigido inicialmente por Guarnerio (Irnerio), cerca de 1087, que, incluso, sobrevivió a su muerte con la consolidación de los llamados glosadores ${ }^{10}$. Su método de enseñanza puede ser sintetizado a través de las siguientes peculiaridades:

1. El objeto de estudio se conformaba por el derecho de Justiniano. Fundamentalmente, se emplearía como objeto de estudio, dentro del programa, al codex secundus, es decir,

8 "En efecto, entre los siglos VIII y XI, fragmentos del Corpus Iuris, principalmente el Código, las Instituciones y las Novelas, se conocieron, aunque con diferente intensidad, en la península itálica -reconquistada durante 30 años por Justiniano-, y en el mediterráneo occidental -también reconquistado-, en especial en el sur de Francia. Testimonios de lo antes dicho fueron, en relación con el Código, la publicación de dos obras de fines del siglo VII y principios del VIII: la Summa perusina y la Glosa de Pistoya; en cuanto a las Novelas, son testimonios de ello, la publicación del Epitome Juliani y la Auténtica, ambas redacciones elaboradas inmediatamente después de la muerte de Justiniano, a pesar de la prohibición del emperador de que se comentara su obra; y referente a las Instituciones, es prueba de lo antes dicho la publicación de la Glosa Turinense. El Digesto fue la obra menos conocida y utilizada en esa época, sin embargo, a partir del siglo $\mathrm{x}$, aparecen obras sistemáticas (tratados) sobre el derecho que parecen haber utilizado el Digesto. Los más importantes de estos tratados fueron: las Excepciones Petri y el Brachilogus Iuris Civilis o Corpus Legum, aunque en torno a estas dos obras se discute si fueron anteriores o no al siglo XII, esto es, a la fundación de la Escuela de Bolonia” (Bernal, 2010, pp. 108).

9 “La expresión: 'Segunda vida del derecho romano' fue utilizada por primera vez por Paul Vinogradoff en su obra Roman Law in Medieval Europe y suele identificarse con la 'recepción del derecho romano en Occidente' término acuñado por el jurista alemán Federico Carlos von Savigny en sus múltiples estudios sobre derecho medieval. A esta 'segunda vida' se le asigna, como punto de partida, el 'descubrimiento' de Irnerio -en vísperas del siglo XII-, del Digesto o Pandectas, la sección importante y rica del Corpus Iuris Civilis de Justiniano. Sin embargo, el derecho romano, como todo proceso históricojurídico estuvo en constante evolución desde sus orígenes hasta dicho 'descubrimiento'. Por consiguiente, esa 'segunda vida' y esa 'recepción' respondieron a un desarrollo del derecho romano que, en perpetuo cambio, pasó por muchos momentos de evolución [...]" (Bernal, 2010, p. 107).

10 "[...] después le sucedieron: Bulgarus, que fallece en 1166; Martinus, que vive hasta el mismo 1166; Ugo, que muere en 1170 y Jacobo, cuya existencia finaliza en 1197. A estos estudiosos se sumaron después, Johanes (1175-1245); Bassanius, que fallece en 1197; Azo (1150-1230); Placentinus (1135-192); Pillius (finales del siglo XII e inicio del XIII); Hugolinus, que fallece en 1233; Roffredus, que muere en 1242 y Acursio (1182-1260). Se reconoce que fueron ellos, quienes, con sus estudios, establecieron los fundamentos del desarrollo de la moderna ciencia del derecho" (Bernal, 2010, pp. 158-159). 
el Digesto (Pandectas en griego, Digestum en latín), el cual hacia parte del Corpus Iuris Civilis (que se completaba con el Codex repetitae praelectionis, las Institutas y las Novellas constitutiones). Dicho texto compilaba diversas opiniones y conceptos de 40 juristas romanos de diversos aspectos del propio derecho ciudadano de Roma, desde los principios generales pasando por elementos de las acciones, la propiedad, derechos reales, contratos, instituciones del ámbito familiar y de sucesiones hasta el derecho penal, entre otros. De cualquier modo, se hace necesario destacar el carácter casuístico por medio del cual se estructuraba dichos textos.

Solo de manera excepcional se empleó como objeto de estudio las diversas manifestaciones jurídicas que estaban vigentes, como el propio derecho canónico, introducido hacia la segunda mitad del siglo XII ${ }^{[11]}$.

2. Lecturas programadas y guiadas. Las clases giraban en torno a la lectura del profesor, quien era el encargado de aclarar las dudas o equivocaciones de los textos. Estos textos eran manuscritos de los propios estudiantes, que solían después alquilar a otros, dada la ausencia de la imprenta. Por su parte, los estudiantes que no contaban con dicho texto se veían obligados a aprendérselo de memoria.

3. Las glosas como forma de comprensión y explicación de los textos. Debido que los textos se encontraban en un lenguaje antiguo, la intervención docente funcionaba como una aparente traducción y una contextualización de lo leído. Por ello, estudiado el texto, el maestro se encargaba de referirse a términos, frases o ideas con el fin que los estudiantes pudieran glosarlas:

Las glosas dictadas por el maestro eran copiadas por el estudiante entre los renglones del texto; al hacerse más largas invadían los márgenes. Pronto las glosas escritas tuvieron una autoridad igual a la del propio 
texto glosado. Cerca del año 1250, la Glossa Ordinaria de Accursio llegó a ser la obra autorizada del Digesto en conjunto (Berman, 1996, p. 140).

4. El uso de elementos y métodos escolásticos para el análisis. Pese a que se ha presumido el origen laico de la Escuela de Bolonia, eso no evitó que se emplearán elementos y métodos de la enseñanza escolástica. Efectivamente, al igual que en otras universidades occidentales dentro de los siglos XII y XIII, se utilizó como forma para comprender el derecho un método equivalente al implementado para la teología. Así en el derecho también se empezó a suponer la autoridad indiscutible de ciertos libros, y pasó a considerarse como un cuerpo que, a pesar de sus posibles contradicciones o lagunas, puede ser reconciliado, integrado y completado mediante las labores del método dialéctico. Precisamente:

[...] como en el caso de la teología, el conjunto del texto escrito, el Corpus Iuris Civilis, como la Biblia y los escritos de los Padres de la Iglesia, fue reconocido como sagrado, como encarnación de la razón. Pero el interés en reconciliar las contradicciones dio al jurista occidental del siglo XII, al tratar de conceptos y reglas jurídicas, mayor libertad y flexibilidad, que las de sus predecesores romanos (Berman, 1996, p. 142).

5. De allí que sean útiles las herramientas propias como ${ }^{12}$ : 1) las distinciones, que implicaban ramificaciones de los diferentes conceptos estudiados; 2) las generalia o brocarda, que se hacían mediante la formulación de las reglas de derecho, que podían reunirse a través de colecciones; 3) los casos, que serían desarrollos prácticos a título de ejemplo;

4) las disensiones de los señores, que muestran las diversas opiniones de los maestros más relevantes, las cuales solían estar en contravía y, por tanto, daban espacio para la 
discusión; 5) las cuestiones, que se basaban en problemas jurídicos y permitían exponer las argumentaciones de los roles contradictorios, para finalizar la conclusión del maestro (solutio), y 6) la summae, que se trata de la condensación de obras ${ }^{13}$.

Asimismo, serían usadas las orientaciones provenientes de la época altomedieval, caracterizadas por las "artes liberales", las cuales se agrupaban en el trivium y el quadrivium:

\begin{abstract}
En la primera de las ramas se enseñaba la gramática (arte de expresarse correctamente, tanto en forma oral como por escrito), la retórica (arte de convencer acerca de la verdad y bondad de las afirmaciones) y la dialéctica (arte de examinar, analizar y discutir lo que se expresaba). La segunda rama (el Quadrivium) correspondía a los estudios científicos, y en ella se aprendían geometría, aritmética, astrología y música. Pues bien, dentro del Trivium, y en relación con la retórica y la dialéctica, se estudiaban nociones de derecho utilizando fuentes justinianeas, es especial el Código y las Instituciones (Bernal, 2010, p. 109).
\end{abstract}

Ahora bien, el modelo universitario de Bolonia hizo parte de un primer modelo de universidades denominadas espontáneas, según su aparición, es decir, de aquellas escuelas que existieron y solo de manera posterior fueron reconocidas como tal. Entre ellas se cuentan universidades, además de Bolonia, como la de París y Oxford, entre otras, que se contraponen con el segundo modelo de universidades creadas, las cuales se establecieron, desde órdenes reales o clericales, con un fin propio antes de su aparición. Normalmente, las universidades espontáneas tenían precedentes en las escuelas catedralicias o monacales. Como ejemplo de las universidades creadas están las universidades españolas tales como 
Salamanca y Alcalá de Henares, las cuales serían los modelos que inspiraron las fundaciones universitarias en América ${ }^{14}$. Finalmente, existe un tercer grupo de universidades, según su forma de aparición, que son aquellas que surgen por traslado o secesión, tal como sucedió con el traslado de la Universidad de Lisboa a Coimbra y de Cambridge, que nacería como disgregación de Oxford, debido a disputas y emigración de un grupo de estudiantes.

Como es de esperarse, el modelo de Bolonia y de las universidades espontáneas serían los faros de orientación para las modalidades sucesoras. Por tanto, Bolonia y París, en el ámbito sustancialmente jurídico, modelarían los llamados mos italicus y mos gallicus.

\section{Mos italicus tardío y mos gallicus}

El mos italicus y mos gallicus son formas de acercamiento a lo jurídico; se desarrollaron bajo una visualización comprensiva y de entendimiento basada, en conexidad escolástica, con el argumentum ad verecundiam o magister dixit. Sin embargo, esta se llevó más a su extremo en las manifestaciones del mos italicus. Justamente, dicho modo de enseñanza plantearía una técnica en la cual se aceptaba como cierta o verdadera una proposición científica

14 "La primera universidad erigida por los españoles en el Nuevo Mundo fue la de Santo Domingo, en la Isla Española (28 de octubre de 1538). La última fue la de León de Nicaragua, creada por decreto de las Cortes de Cádiz del 10 de enero de 1812. Entre ambas fechas sumaron 32 las fundaciones universitarias, si bien algunas, como la de la Plata o Charcas (Bolivia); la de Mérida (Yucatán, México) y la de Buenos Aires (Argentina) solo existieron de jure, pues no llegaron a funcionar plenamente antes de la conclusión del periodo colonial. Una de ellas, la de Oaxaca (México), se quedó en trámites y varias se extinguieron antes que finalizara el régimen colonial, entre ellas algunas establecidas por la Compañía de Jesús, cuyos privilegios para graduar cesaron a raíz de su expulsión de todos los dominios españoles. La mayoría de las universidades coloniales fueron a la vez pontificias y reales. Las creadas por las órdenes religiosas, autorizadas por el papa para otorgar grados, gozaron de este carácter en virtud del privilegio general conferido a la Orden. En muchos casos, la bula pontificia precedió a la real cédula, especialmente en el caso de universidades fundadas por iniciativa de las órdenes religiosas. En otros, la Corona tomó la precedencia, naciendo así las universidades de carácter real, siendo después que adquirieron los privilegios pontificios. Tal sucedió con las universidades de San Marcos de Lima y México (1551), San Carlos de Guatemala (1676), San Cristóbal de Huamanga y Caracas. Algunas no llegaron a recibir el reconocimiento papal, como sucedió con las de La Plata o Charcas y Santiago de la Paz, por haberse extinguido tempranamente. Otras, sobre todo las creadas a fines del siglo XVIII o principios del XIX, no lo obtuvieron nunca. Una Universidad, la de León de Nicaragua, fue autorizada por las Cortes de Cádiz, aunque la Corona la confirmó después de la restauración por real cédula” (Tünnermann, 1996, pp. 125-126). 
apriorísticamente bajo el sustento de quién lo decía o dónde se encontraba contenida; usando los términos de Humberto Maturana, se formulaba a partir de un modelo de objetividad trascendental ${ }^{15}$. Estos acaecimientos llevaron a Bernardo de Chartres, citado por Juan de Salisbury, en el siglo XII, al hablar que los defensores del mos italicus, eran: "Quasi nanos gigantum humeris insidentes". Esta frase no solo se constituía como crítica a la forma de enseñanza, sino que, al tiempo, manifiesta apreciación de rechazo hacia la metodología que concebía, con extrema rigidez, a la ciencia jurídica como efecto de dogmas o axiomas específicos ${ }^{16}$; estos, en algunos casos, eran provenientes, ante la ausencia de un derecho técnico propiamente dicho, desde algo similar a lo que se conoce en la actualidad como doctrina, que en términos precisos sería la communis opinio doctorum como fuente del derecho.

El mos italicus tardío, o bartolismo, se orientó desde la Universidad de Perugia, bajo la figura Bártolo de Sassoferrato. La influencia de este jurista llevó a señalar durante su época que "nemo bonus iurista, nisi sit Bartolista"17. Bártolo conformaría la escuela de los postglosadores o comentaristas (iniciada por su maestro, Cino da Pistoia) y que tendrán su apogeo durante los siglos XIV y XV. A diferencia de la escuela de Irnerio, los comentaristas ampliaban su labor y no se limitaba a aclarar los textos estudiados, sino que hacían un mayor énfasis en el estudio del llamado ius commune ${ }^{18}$, conformado tanto por el derecho romano como por el derecho canónico; el de las corporaciones; por la costumbre, el derecho de fueros y fazañas ${ }^{19}$, y aquellas producciones sustentadas en la

\footnotetext{
15 "Es en este camino explicativo donde una pretensión de conocimiento es una demanda de obediencia” (Maturana, 1997, p. 22)

16 "La ciencia jurídica encontró su autoridad natural en el Corpus Iuris justinianeo". (Guzmán, 1976, p. 17)

17 "Para los juristicas medievales y los «bartolistas» de comienzos de la Edad Moderna este Derecho es la «ratio scripta», un «donum Dei» y su actitud ante él fue de sumisión completa, sin espíritu crítico ante los textos que manejaban. Esto lleva a concluir a muchos estudiosos de hoy que la Jurisprudencia medieval estuvo dominada por el principio de autoridad, de la autoridad del Derecho romano fundamentalmente". (Carpintero, 1977, p. 109)

18 Sobre el ius comune medieval, entre otros: (Tomás y Valiente, 1994; Pérez, 1999; Fernández, 2004; De Castro-Camero, 2010).

19 Los fueros eran normas jurídicas dictadas que concedían privilegios o la condonación de sanciones. Fueron utilizados principalmente en la Alta Edad Media castellana y tenían como finalidad, al igual que las llamadas "cartas pueblas", ayudar a la repoblación de los territorios. Sin embargo, los fueros eran empleados, especialmente, para asentamientos urbanos y las "cartas pueblas" para asentamientos rurales. Los fueros eran similares a las forales (forais) empleadas en Portugal y a los llamados
} 
iurisdictio. Por tanto, solían ver el derecho más desde la casuística y observarlo no como un mero texto, sino como una materia ser integrada en sí (Guzmán, 1976, p. 28):

Para ellos el "Corpus luris" es algo absolutamente práctico cuya utilización no requiere conocimientos especiales de orden histórico, filosófico o literario. Aceptan la edición del "Corpus luris", conocida como "littera vulgata" y ni siquiera los "bartolistas" de la primera mitad del siglo XVI [...] se cuidan de esclarecerlas mediante análisis filológicos o históricos. La literatura, para ellos, es solo un instrumento imprescindible para expresarse, tanto más útil como breve y compendiosa fuera. En consecuencia, el latín empleado está plagado de abreviaturas y su lectura es imposible si no se dispone de un instrumento auxiliar adecuado (Carpintero, 1977, p. 114).

En lo que respecta a su método de enseñanza y abordaje, suele ser resumido así: "promitto, scindo, summo, casumque figuro, prolego, do causas, connoto, obiicio":

Esto significa: análisis crítico del texto a fin de escoger la lectura más correcta (prolego); presentación del problema en su conjunto (promitto); análisis de los distintos elementos del problema (scindo); colocación de ejemplos y figuras análogas (casum figuro); enunciación de las cuatro causas aristotélicas atenientes al problema (do causas); formulación de reglas generales (connoto); recapitulación y especición general del punto de vista de los resultados obtenidos (summo); autoformulación de objeciones y sus respuestas (obiicio) (Guzmán, 1976, pp. 27-28).

El carácter restrictivo de las herramientas a emplear para la comprensión del derecho por parte de los comentaristas fue una

estatutos municipales medievales, pero aquellos podían ser dictados por los reyes o por los propios habitantes del lugar. Por su parte, las fazañas eran decisiones de los jueces y excepcionalmente del rey, basadas en las costumbres regionales, aunque en ocasiones dependían del libre albedrío de quién las otorgaba. Se usaban, también, para el otorgamiento de privilegios en casos concretos, cuando estos no habían sido favorecidos por los fueros. Con el paso del tiempo, las fazañas ayudaron a formar un tipo de antecedentes judiciales que fueron tomando fuerza vinculante (costumbre judicial).

Véase Rabinovich (2007). 
de las razones fundamentales para que los representantes del mos gallicus presentaran sus oposiciones. Conocidos como los humanistas, retomaron las ideas clásicas y propusieron una reconstrucción del derecho desde lo histórico, filosófico, filológico y lingüístico; con ello se alejaron de la práctica y tuvieron una propensión más a lo teórico: "Se llamó así porque encontró su hogar en Francia, en especial en la Universidad de Burdeos" (Bernal, 2010, p. 138).

Nacido el mos gallicus a mitad del siglo XVI, sus seguidores dejaron de considerar al derecho romano como una obra ajena al tiempo y al espacio, y procuraron reconstruirlo desde una contextualización e introduciendo elementos literarios para la comprensión del derecho. Entre los diversos defensores de este modelo se encuentran Andrea Alciato, jurista italiano que se trasladó a Francia por su descontento con el mos italicus tardío y fundó en Bourges una escuela jurídica humanista, donde tuvieron cabida, como primeros estudiantes, Guillaume Budé y Ulrich Zasius. Con esto "Francia se convirtió en el país clásico del humanismo jurídico, y entre sus números cultivadores cabe recordar a $\mathrm{F}$. Baron, D. Godofroi y, sobre todo, a J. Cuyaz (Cuiacius, 1522-1590), considerado el más grande humanista” (Guzmán, 1976, p. 31).

Tal como se anticipaba, la consecuencia primordial de esta escuela se relacionará con la relativización de la autoridad que se le había otorgado al derecho romano: siendo un derecho contextual no puede, entonces, esperarse que fuese aplicado y asumido como palabra última, y más si se confunde el derecho romano con las citas y explicaciones de los juristas de los siglos XIV al XVI. En esa medida, los defensores de esta perspectiva discutieron las conclusiones sacadas por los representantes del mos italicus tardío, y solo acudieron a ellos y a sus ideas para desprestigiarlos.

El objeto de estudio de los humanistas franceses fue [...] -además de los textos extrajurídicos [...]-, trabajaron sobre algunas obras jurídicas anteriores y posteriores a la compilación justinianea. Así, dedicaron sus esfuerzos al Breviario de Alarico, editado por Sichardo, humanista de Basilea en 1528, y al Código Teodosiano, que cuenta con un excelente comentario de Jacobo Godofredo que todavía se usa. También a la Paráfrasis de Teófilo 
a las Instituciones de Justiniano, comentada por Viglio quien, además, reeditó el Hexábiblos de Hermenópulus, así como a las Basílicas de Léon el Filósofo, obra del derecho romano oriental, muy estudiada por Cuyacio y que Fabrot tradujo al latín. También se dedicaron los humanistas a la reconstrucción de fuentes romanas como la de la Ley de las XII Tablas y la del Corpus Iuris Civilis, realizadas estas por los dos Godofredo. Por otra parte, en su empeño de volver al clasicismo, afianzado por su aversión a los juristas de la corriente del mos italicus, los humanistas galos pusieron en tela de juicio, no solo la labor "antihistórica" llevada a cabo por los glosadores contenida en la Glosa de Acursio, sino también la autenticidad del manuscrito pisano-florentino y de la Littera Vulgata, supuestamente trabajados por Irnerio (Bernal, 2010, p. 139).

Guiados por dichos materiales principalmente, los humanistas tuvieron una variada producción tanto en obras como en estilos. Con todo, se hizo común el regreso a las glosas y al empleo de comentarios, solo que de forma distinta a las estructuras de sus predecesores:

Su actividad consistió en glosar el derecho romano, normalmente mediante el sistema de letras intercaladas en el texto principal. Estas letras corresponden a otras tantas notas a pie de página o marginales en las que se explica el significado de una expresión o de un término. Así, el texto romano aparece como lo más importante, y la actividad de estos nuevos glosadores tiende solamente a esclarecer su sentido (Carpintero, 1977, p. 126)

Esto último se hace a través de herramientas filológicas, históricas y literarias, como se había advertido:

En el siglo XVII, el humanismo jurídico comenzó a conocerse en Francia con el nombre de Escuela Culta, siendo Cuyacio y Doneau sus principales representantes, y, en Holanda, recibió la denominación de jurisprudencia elegante, destacando Voet y Grocio entre sus cultivadores, siendo este último considerado como uno de los padres del derecho internacional público moderno, sobre la base de las reglas deducidas del Corpus 
justinianeo. En Alemania el movimiento humanístico coincide con la recepción del derecho romano a finales del siglo xv, mediante una Ordenanza del emperador alemán Maximiliano, promulgada en 1495, conforme a la cual se asume como derecho común, y nacional alemán, gemeines Recht, el derecho romano de los glosadores y comentaristas, en detrimento de la casuística de los tribunales y de las normas y costumbres locales, con algunas relevantes excepciones, entre las que cabe destacar, las tradiciones y costumbres propias de Sajonia, contenidas en el denominado Espejo de Sajonia, Sachsenspiegel. La manifestación en la doctrina y la práctica judicial, del asumido como derecho nacional alemán, se conoce con el nombre de usus modernus pandectarum, y supone una síntesis de ideas historicistas y preocupaciones dogmáticas, que constituye el germen de la Escuela Histórica del XVIII y de la Pandectística alemana del XIX (Fernández, 2016, pp. 288-289.

Evidentemente, estos manifestaciones o modelos no fueron uniformes en todos sus contextos ni tampoco se prolongaron indefinidamente. Por consiguiente, serían cambios sustanciales debido al advenimiento de la modernidad, la desaparición de los imperios, la unificación de los Estados, los procesos coloniales, los cuales influyeron para la extensión de diferentes métodos de enseñanza. Muchos de ellos retomaron elementos propios del mos italicus y el mos gallicus, y los adecuaron a sus necesidades, como vistos.

\section{La inserción y expansión de las metodologías itálicas y gálicas}

La contraposición de estos dos métodos fue extensiva en Europa continental, donde se perfilaba, ya dentro de la propia modernidad, al derecho como forma de cohesión dentro de los nacientes estados nacionales. Justamente, la pretensión de separar Iglesia y Estado requirió que se establecieran elementos disimiles a la religión que pudieran unificar al conglomerado social, ya de por sí variado en sus percepciones y orientaciones. Fue así como conceptos, tales como la ley, el principio de legalidad, el Estado de Derecho, entre otros, 
fortalecieron la idea de imparcialidad, seguridad y unificación de la nueva forma de organización política surgida desde el contrato social. Claramente ante la ausencia de una forma religiosa única que agrupara al colectivo, el derecho se convirtió en el modo de regulación primaria. En ese sentido, la enseñanza y la asimilación normativa primó para darle vida al Leviatán y limitar sus propios poderes frente a los ciudadanos. De allí que nacieran diferentes escuelas y métodos de enseñanza como la exégesis, la histórica, la jurisprudencia dogmática, la jurisprudencia de conceptos, la jurisprudencia de intereses, la científica, del derecho libre, entre otras, que fueron abriéndose cabida en la formulación e interpretación del derecho. Si bien por cuestiones de extensión no podrán ser tratadas dichas escuelas a fondo, se ha concebido que pueden ser caracterizadas mediante cuatro fundamentos básicos; ellos son: (1) Las fuentes del derecho; (2) las herramientas interpretativas; (3) la labor del jurista; y (4) la percepción de verdad. Respecto a las fuentes del derecho, se han tomado tres criterios básicos, según sea la percepción: 1) si se toma la ley como única fuente o fuente principal; 2) si se aceptan otras piezas normativas, a la ley, como fuente del derecho (o se evita la posición reduccionista de la ley como fuente única), y 3) si se toma en cuenta el contexto como elemento determinante o coadyuvante de las fuentes normativas. Estas variaciones, con esas tres orientaciones sobre las fuentes, dependen de si, como se verá, existe una sola determinación o dos en conexión: así si se señala que la escuela adopta la ley y otros aspectos jurídicos, estaremos diciendo, por ejemplo, que concibe la ley como fuente principal, pero no excluyente.

Por su parte, respecto a las herramientas normativas se ha empleado solo dos categorías de definición: los preceptos normativos y los contextos. En algunos casos los primeros serían excluyentes, y en otros, solo necesarios, e incluso contingentes (cuando solo se habla de contextos).

En materia de la labor del jurista se tienen tres funciones: crear derecho, interpretarlo o integrarlo para darle armonía al sistema jurídico. Difícilmente, las escuelas que se estudian aceptan ese papel creativo, lo que influencia, directamente, la forma de enseñanza de lo normativo; por el contrario, el papel suele estar más cercano a la consideración de que el jurista integra, dado que toda respuesta se encuentra en el ordenamiento jurídico o en su defecto puede 
interpretar, sea porque hay derecho "oscuro" o se acepta el derecho como una expresión lingüística-contextual.

Finalmente, se alude a la visión que se tiene sobre la verdad como representación científica, con lo cual se habla de una única o trascendental, cuando es objetiva, o, en su defecto, existen varias verdades subjetivas.

Dadas las anteriores explicaciones, tenemos que las escuelas mencionadas se caracterizan dependiendo de su relación así (tabla 1):

\begin{tabular}{|c|c|c|c|c|c|c|c|c|c|c|}
\hline \multirow{2}{*}{ 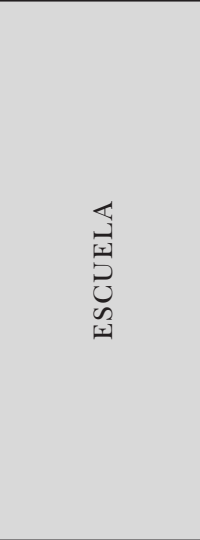 } & \multicolumn{3}{|c|}{ 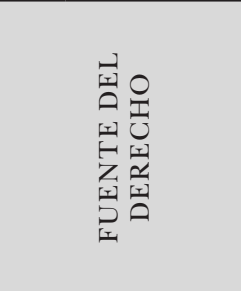 } & \multicolumn{2}{|c|}{ 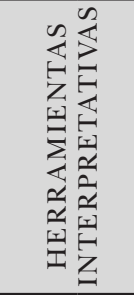 } & \multicolumn{3}{|c|}{ 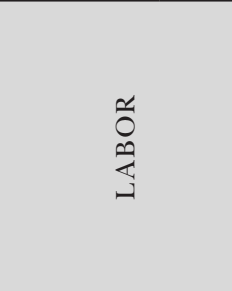 } & \multicolumn{2}{|c|}{$\begin{array}{l}\stackrel{\vartheta}{a} \\
\stackrel{2}{a} \\
\frac{1}{>}\end{array}$} \\
\hline & 空 & 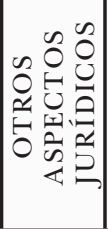 & $\begin{array}{l}0 \\
\qquad \\
x \\
y \\
y \\
z \\
0 \\
0\end{array}$ & 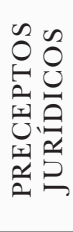 & \begin{tabular}{l}
0 \\
0 \\
$\qquad$ \\
$x$ \\
\multicolumn{1}{c}{} \\
$z$ \\
0 \\
0 \\
0
\end{tabular} & 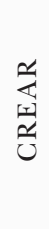 & 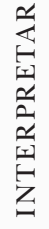 & 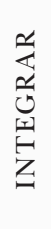 & 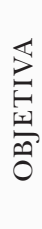 & 点 \\
\hline Exégesis & $\sqrt{ }$ & & & $\sqrt{ }$ & & & & $\sqrt{ }$ & $\sqrt{ }$ & \\
\hline Histórica & $\sqrt{ }$ & $\sqrt{ }$ & & & $\sqrt{ }$ & & $\sqrt{ }$ & $\sqrt{ }$ & & $\sqrt{ }$ \\
\hline $\begin{array}{c}\text { Jurisprudencia } \\
\text { Dogmática }\end{array}$ & & $\sqrt{ }$ & $\sqrt{ }$ & $\sqrt{ }$ & & & & $\sqrt{ }$ & $\sqrt{ }$ & \\
\hline $\begin{array}{l}\text { Jurisprudencia } \\
\text { de conceptos }\end{array}$ & & $\sqrt{ }$ & & $\sqrt{ }$ & $\sqrt{ }$ & & $\sqrt{ }$ & & $\sqrt{ }$ & \\
\hline $\begin{array}{c}\text { Jurisprudencia } \\
\text { de intereses }\end{array}$ & $\sqrt{ }$ & & $\sqrt{ }$ & $\sqrt{ }$ & $\sqrt{ }$ & & $\sqrt{ }$ & $\sqrt{ }$ & & $\sqrt{ }$ \\
\hline $\begin{array}{l}\text { Científica } \\
\text { francesa }\end{array}$ & & $\sqrt{ }$ & & $\sqrt{ }$ & $\sqrt{ }$ & & $\sqrt{ }$ & $\sqrt{ }$ & $\sqrt{ }$ & \\
\hline Derecho libre & & & $\sqrt{ }$ & & $\sqrt{ }$ & $\sqrt{ }$ & & & & $\sqrt{ }$ \\
\hline
\end{tabular}

Tabla 1. Caracterización de las escuelas del derecho moderno Fuente: elaboración propia. 
De la caracterización efectuada se extraen ciertos elementos conclusivos:

1. Estos desarrollos que se relacionan, con más cercanía, con el mos italicus. Ciertamente, las limitaciones sobre la labor creativa, la conexión con una única verdad y las labores, prevalentemente, de integración muestran esa intención de conservar el derecho como un ordenamiento cerrado, hermético y completo, que, excepcionalmente, puede recurrir a elementos contextuales (desde el punto de vista histórico). Si bien escuelas como la jurisprudencia de intereses y el derecho libre modifican, de cierta forma, estas percepciones, no tuvieron un desarrollo tan vinculado propiamente con la teoría jurídica, sino con el derecho desde un ámbito sociológico y lingüístico.

2. Con cierta relación a lo anterior, la observación de una verdad objetiva permitió alcanzar cierto estatus basado en las seguridades y certezas que no podrían ser acatadas cuando se valoran las múltiples percepciones. Si bien ello no pasó con la escuela histórica, dado que tuvo gran influencia a través de Friedrich Karl von Savigny, su desarrollo se encontraba en una época de integración donde era necesaria dicha vertiente. Así se entiende que en la controversia entre el mos italicus y el mos gallicus triunfó el primero:

Independientemente del auge del mos gallicus en los ambientes universitarios de Europa, lo cierto es que, en la práctica forense, la influencia que tuvo la actitud erudita e historicista de los miembros de esta corriente fue muy modesta. Los jueces y abogados prefirieron el mos italicus, basado en las reinterpretaciones de los postglosadores al Corpus Iuris, debido a que a través de ellas obtenían un alto grado de seguridad jurídica que facilitaba sus actuaciones ante los tribunales de justicia (Bernal, 2010, p. 138). 
3. Estos elementos consentirán, entonces, una configuración donde permaneciera, con sus modificaciones, el uso de los llamados argumentos de autoridad, generalmente, ya no desde la fuente o persona en los cuales se basaba, pero sí por la idea de mantener el uso de método específico, con carácter científico. De este modo, las estructuras formativas mantuvieron similitudes ciertas con la enseñanza, incluso de Bolonia, siguiendo textos puntuales y creando tradiciones a partir de los maestros y sus propuestas de interpretación de la ley o el ordenamiento.

En ese contexto, debe también incluirse el caso latinoamericano. Ciertamente, como se nombró con anterioridad, el modelo de enseñanza del contexto de América Latina se derivó, por decirlo de algún modo, genéticamente de las universidades tales como la de Salamanca, en la cual existiría una afinidad directa con la expresión del mos italicus tardío. Esto permitiría que se acogieran teorías y métodos derivados de esta corriente. Puntualmente, se ha nombrado a la escuela latinoamericana, de manera extendida, como clasicismo jurídico (López, 2004), en la cual se percibe una amalgama de elementos de escuelas como la exegética, conceptualista y la histórica, principalmente. Su naturaleza e idiosincrasia mantuvo ese direccionamiento del reconocimiento de verdades objetivas para el derecho y el uso de la ley desde un sentido formalista, con lo cual se extendió una permanencia, en la mayor parte de los casos, de estructuras decimonónicas y vinculadas con el estado legal de derecho y, a su vez, desligándose de los contextos u otras fuentes normativas.

Con todo, la implementación, por ejemplo, para el caso latinoamericano de lo que fue llamado el nuevo constitucionalismo ${ }^{20}$

20 "La andadura de este nuevo constitucionalismo latinoamericano puede remontarse a procesos constituyentes como el brasileño, en 1988, o el colombiano, en 1991. Y ha cobrado renovado impulso con los recientemente abiertos en países como Venezuela, Ecuador o Bolivia. Estos procesos han estado marcados, entre otros elementos, por la irrupción de actores constituyentes (movimientos campesinos, indígenas, organizaciones de mujeres y feministas, sindicatos nuevos y antiguos, movimientos de desocupados, pobres urbanos y afrodescendientes, organismos de derechos humanos) que han forzado la inclusión de nuevos temas en la agenda político-constitucional, y con ello, la delimitación de un modelo con perfiles propios" (Pisarello, 2009, p.2). Véase, también: (Martínez, 2008; Sosa, 2012; Uprimny, 2011; Villabella, 2010). 
trajo consigo una nueva órbita de acción, que ha involucrado el reconocimiento de otras fuentes y criterios auxiliares que maximizan la labor creativa del jurista y, en consecuencia, indican la necesidad de nuevos métodos de enseñanza. Sin embargo, esto escapa del presente resultado parcial de la investigación.

\section{Conclusiones}

Finalizada la exposición del actual artículo, es posible hablar de tres conclusiones sobre la génesis de la profesión y formación jurídica de la tradición de occidental:

1. Resulta llamativo que el derecho, entendido como proyecto asimilativo y de enseñanza, se haya restringido, debido a su desarrollo universitario y, posteriormente en su idea de actividad científica, a procesos monodisciplinarios y autorreferentes. A lo sumo, en ciertas ocasiones, ha aceptado el uso de herramientas de la lingüística y la historia, fundamentalmente, pero con fines de interpretación, más que de explicación de la ciencia jurídica, con lo cual se aleja de un entorno y de su práctica como forma de regulación con fines específicos.

2. Justamente, no hay un uso articulado de otras disciplinas. Si bien el derecho podría tener una perspectiva multidisciplinar, si por ello se entiende el reconocimiento de otras disciplinas cohabitantes del saber, pero no coadyuvantes, no parece como válido su desarrollo, en estas primeras manifestaciones, como un asunto de inter y transdisciplinariedad. Precisamente, herederos de esos modelos iniciales, desde Bolonia y París, las diferentes universidades de corte europeas continental, incluyendo las latinoamericanas, han mostrado una resistencia, casi genética, a la introducción de otras disciplinas en el estudio de lo jurídico.

3. Así las cosas, la formación jurídica ha sido más cercana en un proceso más cercano a la repetición y a los argumentos 
de autoridad donde se depende fundamentalmente de la capacidad inicial de quién lo desarrolla y el estatus que se ha recibido, lo cual debilita, también, esa interacción con otros espacios y disciplinas, y vuelve rígido y paquidérmico la transformación del derecho y su enseñanza, lo que fácilmente lograba que el derecho y su realidad estuviese lejos de la facticidad y el contexto.

\section{Referencias}

Agudo, A. (2010). Oriente y Occidente: Dos modelos de enseñanza del Derecho Romano. REDUR, (8), 7-24. Recuperado de http://www. unirioja.es/dptos/dd/redur/numero8/agudo.pdf

Barcala, A. (1985). Las universidades españolas durante la Edad Media. Anuario de Estudios Medievales, (15), 83-126. Recuperado de http:// digital.csic.es/bitstream/10261/16115/1/20090728144734682.pdf.

Berman, H. (1996). La formación de la tradición jurídica de occidente. México: Fondo de Cultura Económica.

Bernal, B. (2010). Historia del derecho. México: Nostra Ediciones.

Binder. A. (2005). El mercado de los servicios legales y la crisis de la abogacía. Abogacía y Educación Legal, (9), 62-65. Recuperado de http://www.sistemasjudiciales.org/content/jud/archivos/ notaarchivo/436.pdf

Carpintero, F. (1977). 'Mos italicus', 'mos gallicus' y el humanismo racionalista. Una contribución a la historia de la metodología jurídica. Ius Comumne, (6), 107-172. Recuperado de http://www. franciscocarpintero.com/pdf/ArtiRev/\%E2\%80\%9CMos\%20 italicus $\% \mathrm{E} 2 \% 80 \% 9 \mathrm{D}, \% 20 \% \mathrm{E} 2 \% 80 \% 9 \mathrm{Cmos} \% 20$ gallicus $\% \mathrm{E} 2 \% 80 \% 9 \mathrm{D} \% 20 \mathrm{y} \% 20 \mathrm{el} \% 20 \mathrm{Humanismo} \% 20$ racionalista, $\% 20$ en\%20\%E2\%80\%9CJus\%20Commune\%E2\%80\%9D.pdf.

De Castro-Camero, R. (2010). Ius commune: fundamento del derecho común europeo e iberoamericano. Breve Aproximación. Boletín Mexicano de Derecho Comparado, (128), 671-700. Recuperado de http://www.redalyc. org/articulo.oa? $\mathrm{id}=42719870004$

Fernández, A. (2004). Un derecho sin espacios: derecho romano, ius commune y derecho común europeo. Anuario da Facultade de Dereito da Universidade da Coruña, 8, 311-330. Recuperado de https://uc.udc.es/dspace/bitstream/handle/2183/2307/AD818. pdf;jsessionid=8CF2BDE2283D2A43CB543423147AF83B? sequence=1

Fernández, A. (2016). Ciencia jurídica europea y derecho comunitario: Ius romanum, Ius commune, common law, civil law. Glossae. European Journal of Legal History, (13), 275-306. Recuperado de https://dialnet.unirioja. es/servlet/articulo?codigo $=5845496$ 
Guzmán, A. (1976, julio). 'Mos italicus’ y 'Mos gallicus'. Conferencia presentada en Aula Magna de la Facultad de Derecho de la Universidad de Chile, Santiago, Chile. Recuperado de https:// hdunab2010.files.wordpress.com/2010/04/20-guzman-britoalejandro-mos-italicus-y-mos-gallicus.pdf

Kuhn, T. (2002). Estructura de las revoluciones científicas. México: Fondo de Cultura Económica.

López, D. (2004). Teoría impura del derecho. La transformación de la cultura jurídica latinoamericana. Bogotá, D.C.: Universidad de los Andes, Legis.

Magallón, J. (2002). El renacimiento medieval de la jurisprudencia romana. México: Universidad Nacional Autónoma de México.

Martínez, R. (03 de septiembre de 2008). El constitucionalismo "sin padres" y el proyecto de Constitución de Ecuador. Razón Pública. Recuperado de http://www.razonpublica.com/index.php/internacionaltemas-32/30-el-constitucionalismo-qsin-padresq-y-el-proyecto-deconstitucie-ecuador.html.

Maturana, H. (1997). La objetividad. Un argumento para obligar. Santiago: Dolmen.

Pérez, A. (1999). El ius commune: artificio de juristas. En T. De Montagut (ed.), Història del pensament jurídic. Curs 1996-1997 dedicat a la memòria del professor Francisco Tomás y Valiente (pp. 69-93). Barcelona: Universitat Pompeu Fabra.

Pérez, R. (2004). Los abogados de América Latina. Una introducción histórica. Bogotá, D.C.: Universidad Externado de Colombia.

Pérez, R. (2005). Educación Jurídica, Abogados y Globalización en América Latina. Abogacía y Educación legal, (9), 4-14. Recuperado de http:// www.sistemasjudiciales.org/content/jud/archivos/notaarchivo/428. pdf

Peset, M. (1987). Historia de las universidades, historia de las ciencias. Revista da Faculdade de Letras, 103-117. Recuperado de http://ler.letras. up.pt/uploads/ficheiros/artigo8901.pdf

Pisarello, G. (2009). El nuevo constitucionalismo latinoamericano y la constitución venezolana de 1999: balance de una década, Revista Sin Permiso, (6), 1-18. Recuperado de http://www.rebelion.org/ docs/96201.pdf

Rabinovich, R. (2007). Un viaje por la historia del derecho. Buenos Aires: Quorum

Salvador, J. (2008). La Universidad: un acercamiento histórico-filosófico. Ideas y valores, 57(137), 131-148. Recuperado de http://revistas.unal.edu.co/index.php/idval/article/view/1491.

Sosa, J. (2012). ¿Qué es el "nuevo constitucionalismo latinoamericano"? Entrevista a Rubén Martínez Dalmau. Gaceta Constitucional, (52), 301-308. Recuperado de http://www.gacetaconstitucional.com.pe/ 
sumario-cons/doc-sum/GC\%2052\%20Juan\%20Manuel\%20SOSA\%20 SACIO.pdf

Tomás y Valiente, F. (1994). El "ius commune europaeum" de ayer y de hoy. Glossae, (5-6), 9-16. Recuperado de https://digitum.um.es/xmlui/ handle/10201/27871

Tünnermann, C. (1996). Breve historia del desarrollo de la universidad en América Latina. En La educación superior en el umbral del siglo XXI (pp. 121-141). Caracas: Cresalc. Recuperado de http://www.cibertlan. net/biblio/tidlectrsbascs/Tunnermann.pdf.

Tünnermann, C. (2003). La universidad latinoamericana ante los tetos del siglo XXI. México: Unión de Universidades de América Latina.

Uprimny, R. (2011). Las transformaciones constitucionales recientes en América Latina: tendencias y desafíos. En C. Rodríguez (ed.), El derecho en América Latina. Un mapa para el pensamiento jurídico del siglo XXI (pp. 109-137). Buenos Aires: XXI.

Velásquez, R. y Morales, J. (2010). Historia y Preeminencia de la Universidad Occidental. Ingenio Libre, (10), 1-15. Recuperado de http://www. unilibre.edu.co/revistaingeniolibre/revista10/articulos/historia-ypreeminencia-de-la-universidad-occidental.pdf

Villabella, C. (2010). Constitución y Democracia en el Nuevo Constitucionalismo Latinoamericano. IUS, (25), 49-76. Recuperado de http://187.188.167.138:82/blogvillabella/revista25.pdf 